3 "En la teoría de Alberti, un edificio es la copia de Alberti entre diseño y fabricación, aparece lación definición moderna del arquitecto como autor, en el sentido humanista del término." (trad. a.) (Carpo, 2011 p. X)

${ }^{4} \mathrm{CAD} / \mathrm{CAM}$ son las siglas de computer-aided design y computer-aided manufacturing.

5 "El poder moderno de lo idéntico llegó a su fin con el auge de las tecnologías digitales. Todo lo que es de todos los postulados de lo idéntico que han determinado la historia de las tecnologías culturales occidentales durante los últimos cinco siglos. En arquitectura esto significa el fin de las limitaciones de la notación, de la normalización industrial y más en general, de lificio." (trad. a.) (Carpo, 2011, p. X).

- Una localización que está asociada al cálculo de los elementos disenados, lo que permite su inmediata construccion, por ejemplo a través de impresoras 3D. Al respecto, tal como es explicado por Mario Carpo (2011), una de las principales objeciones a este de resultta a través de un proeso asociativo de monta de las distintas piezas diseñadas y fabricadas.

Tara Beaucé y Cache la existencia de programas de diseño no constituye un valor en sí mismo, así como su utilización tampoco genera cambios en la producción arquitectónica de manera 'mágica'. Para estos autores 'Ahora más que nunca, la arquitectura olrecidas por lo no estándar oportunidades progresivamente y con paciencia, construya una cultura genuina de la producción digital” (2009, p.105).

${ }^{8}$ Para Sennett, el artesano tiene la capacidad de localizar, indagar y develar (2009, p.340), comprometiendo su trabajo con la materialización relexion y construcción de signilicados de u

BIBLIOGRAFÍA

ALBERTI, Leon Battista. De Re Aedificatoria. Prólogo de Javier Rivera. Traducción de J. Fresnillo Núñez. Madrid: Akal, 1991. ISBN 8476009240.

ALLEN, Stan. Practice: architecture, technique and representation. Amsterdam: G+B Arts Internation

BEAUCÉ, Patrick; CACHE, Bernard. "Hacia un modo de producción no estándar". En ORTEGA, Lluis. (Ed.). La digitalización toma el mando. Barcelona: Gustavo Gili, 2009. ISBN 9788425222757 .

CARPO, Mario. The Alphabet and the algorithm. Londres: The MIT Press, 2011. ISBN

CACHE, Bernard. Earth Moves. The furnishing of territories. Cam
0262531305.

CACHE, Bernard. Projectiles. Londres: Architectural Ascociation, 2011. ISBN: 9781902902883.

LYNN, Greg. Animate form. New York: Princeton Architectural Press, 1999. ISBN 1568980833.

LYNN, Greg. (2009). "Una forma avanzada de movilidad”. En ORTEGA, Lluis. (Ed.). La digitalización toma el mando. Barcelona: Gustavo Gili,2009. ISBN

SENNETT, Richard. El artesano. Traducción Marco Aurelio Galmarini. Barcelona: Anagrama, 2009. ISBN Aurelio Galmarini.

\section{ABSTRACT}

La integración de las fases de diseño, representación y fabricación que la tecnología digital permite, abre nuevas posibilidades al proyecto, reemplazando un proceso secuencial por otro simultaneo. Una simultaneidad que se vincula con una concepción arstemal $\mathrm{c}$. conexión interactivo entre la mente y la mano, ente creación y producción, posibiltando un desarrollo colaborativo del proyecto, desafiando la tradicion noción de autoría Los puntos de contacto entre el trabajo artesanal y estas innovadoras tecnologías, permiten pensar a estas últimas como una suerte manufactura digital, capaz de re-significar el vinculo entre conocimiento (software) y materialización (hardware), entre teoría y práctica . En este contexto, la presente investigación plantea una reflexión sobre las implicancias -teóricas y operativas- que esta incorporación tecnológica tiene o puede tener sobre la arquitectura y su desarrollo disciplinar, considerando además los desafíos planteados por la realidad contemporánea.

PALABRAS CLAVE: proyecto; teoría; práctica; representacion; trabajo artesana.

FELIPE ANDRES CORVALAN TAPIA es arquitecto y magíster en Teoría e Historia del Arte por la Universidad de Chile. Es académico del Departamento de Arquitectura FAU, Universidad de Chile y editor de la revista De Arquitectura de la misma Institución.

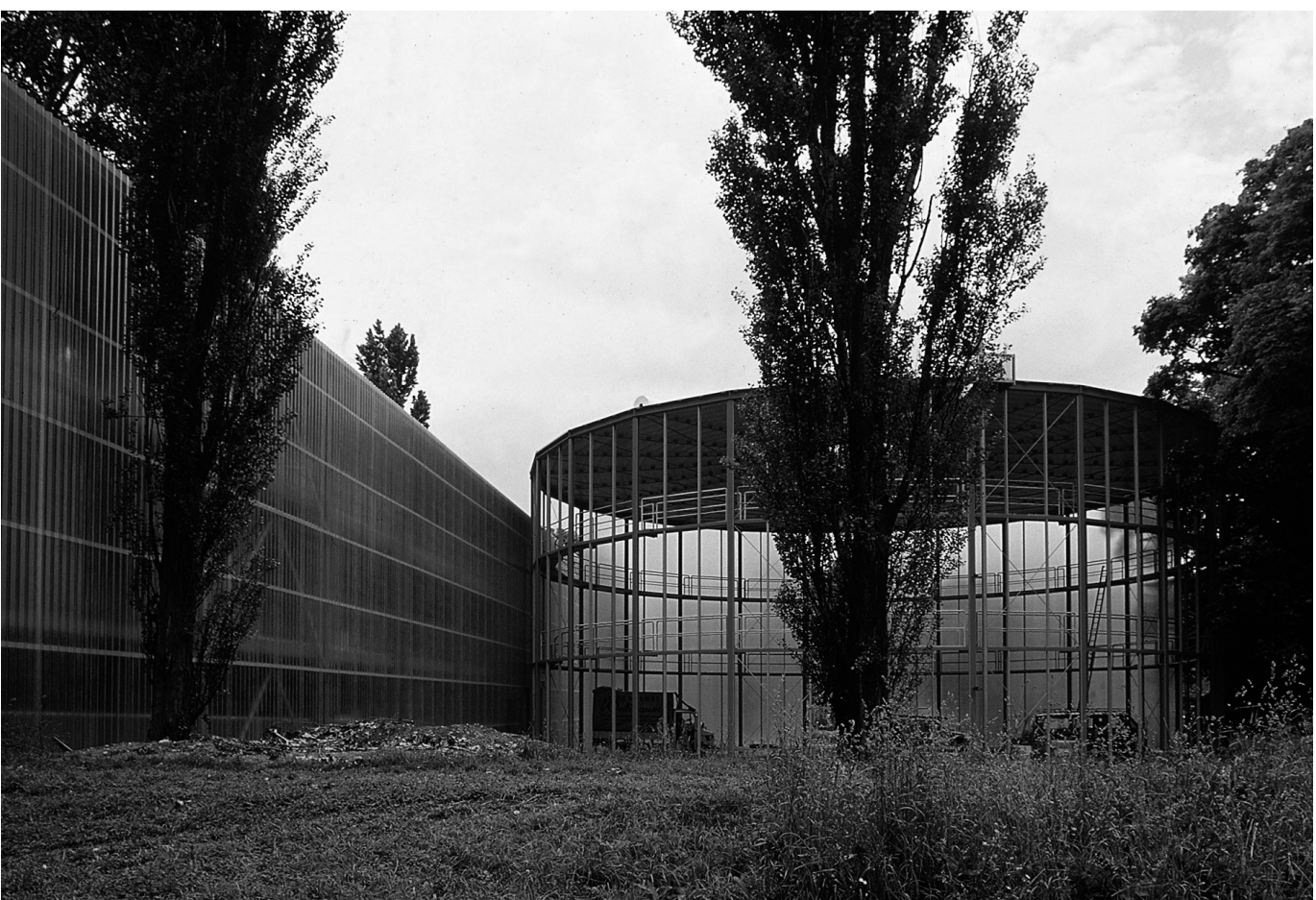

FIG. 1. KRISCHANITZ, A.1988. An der Traisen Pavillion en St. Pölten durante su
construcción. Foto: Margherita Spiluttini. Fuente: AZW. Estudio Krischanitz.

\title{
Proyectos expuestos
}

\section{Pabellón de exposición y debate del nuevo plan urbano de la capital federal en St. Pölten. Austria. 1988. Adolf Krischanitz}

\section{Marta Pelegrín}

Recibido 2016.08.08 *.. Aceptado 2016.08.16 DOI: $10.5821 /$ palimpsesto. 16.5143

L 1989 el Bauherrenpreis ${ }^{1}$ de Austria premia 政 contradictoria de la arquitectura centro europea n el inicio de la década de los noventa: el Pabellón Temporal An der Traisen (St.Pölten, Austria) de Adolf Krischanitz, y la Ampliación del Despacho de Abogados en Falkenstrasse (Viena, Austria) realizado por CoopHimmelb(l)au.

El premio reconoce la sencillez técnica y la belleza con que Krischanitz asume la excepcionalidad² del pabellón temporal para sintetizar y ensayar una propuesta pragmática, operativa y de bajo presupuesto, que difiere significativamente de la complejidad formal y retórica deconstructivista con que la crítica -y la práctica- de la arquitectura lideraban el discurso

El proyecto construye un espacio público con grandes connotaciones simbólicas, para generar un lugar de encuentro lleno de intensa actividad: junto a la exposición "Geburt einer Hauptadt" ("Nacimiento de una Capital"), se celebran presentaciones y jornadas de debate entre ciudadanos y expertos sobre el futuro desarrollo de St. Pölten como capital federal de Baja Austria. El espacio pensado como temporal pabellón de exposiciones es usado para conciertos, obras de teatro y danza, durante diez años hasta su desmontaje y venta.

\section{Proyecto expuesto}

De forma y materialidad enigmática ${ }^{4}$, el pabellón evoca una imagen entre arcaica y futura, entre templo y prototipo industrial expuesto entre las sombras de los álamos del río Traisen. La construcción temporal se compone en dos piezas, un prisma y un cilindro apenas tangentes entre sí, "un espacio que exhibe y un espacio que se exhibe" . El prisma es la "vitrina de exposición"6, una edificación de estructura metálica revestida de paneles ondulados de policarbonato traslúcido (Scobalit) al Norte y de fibrocemento (Eternit) en la fachada Sur. coloreada por el artista Oskar Putz, que despliega una experiencia sensorial única de luminosidad y ligereza. Los tres niveles de forjado flotan en esta envolvente liviana, una doble altura señala el acceso. Las escaleras de conexión situadas fuera de las galerías conducen al visitante por los materiales de la exposición, obras de arte, proyecciones, fotografías y maquetas, que acompañan a la muestra de planeamiento; ejemplos de arquitectura se muestran como posibles piezas de un collage urbano para ilustrar el valor diferencial e identitario que construiría una imagen de futuro para ciudad.

El cilindro de $28 \mathrm{~m}$ de diámetro y $12 \mathrm{~m}$ de altura, realizado también con estructura metálica atornillada y tensada, se cubre con una estructura Tensegrity tipo rueda de bicicleta, según cálculos del ingeniero W. Ziesel, y se reviste del mismo panel ondulado transparente. El espacio genera un ágora democrática, con la rotundidad que le aporta la forma de Tholos, pero sin la pesadez que le aportarían las instituciones que habitualmente representaban esa democracia. Las piezas ensambladas, la cubierta ligera y el revestimiento translúcido evocan un lugar solemne y a la vez cercano al visitante, que se acerca a conocer y reconocerse en la ideación de esta nueva capital.

\section{Ciudad expuesta}

El momento es único: inventar una capital. Los arquitectos D. Steiner, G. Schöllhammer, G. Eichinger y C. Knechtl convocan a artistas, consultores técnicos y críticos para formular los contenidos de la exposición. La identidad histórica y arqueológica de la provincia se documenta ensalzando la relevancia del yacimiento de la Venus de Willendorf y la Biblioteca de la abadía de Melk que inspirara a Umberto Eco para escribir El Nombre de la Rosa (1980), ambos a unos kilómetros de la ciudad.

Tras la declaración del Municipio de Viena como provincia autónoma, la invención de una nueva capital para Baja Austria se suma a los inminentes cambios políticos y territoriales en que estaba inserta la Europa fundada en los mitos modernos (R. Barthes ${ }^{8}$ ) y cuya unión (Maastricht, 1992) conlleva contradictoriamente a la reafirmación de multitud de identidades locales 


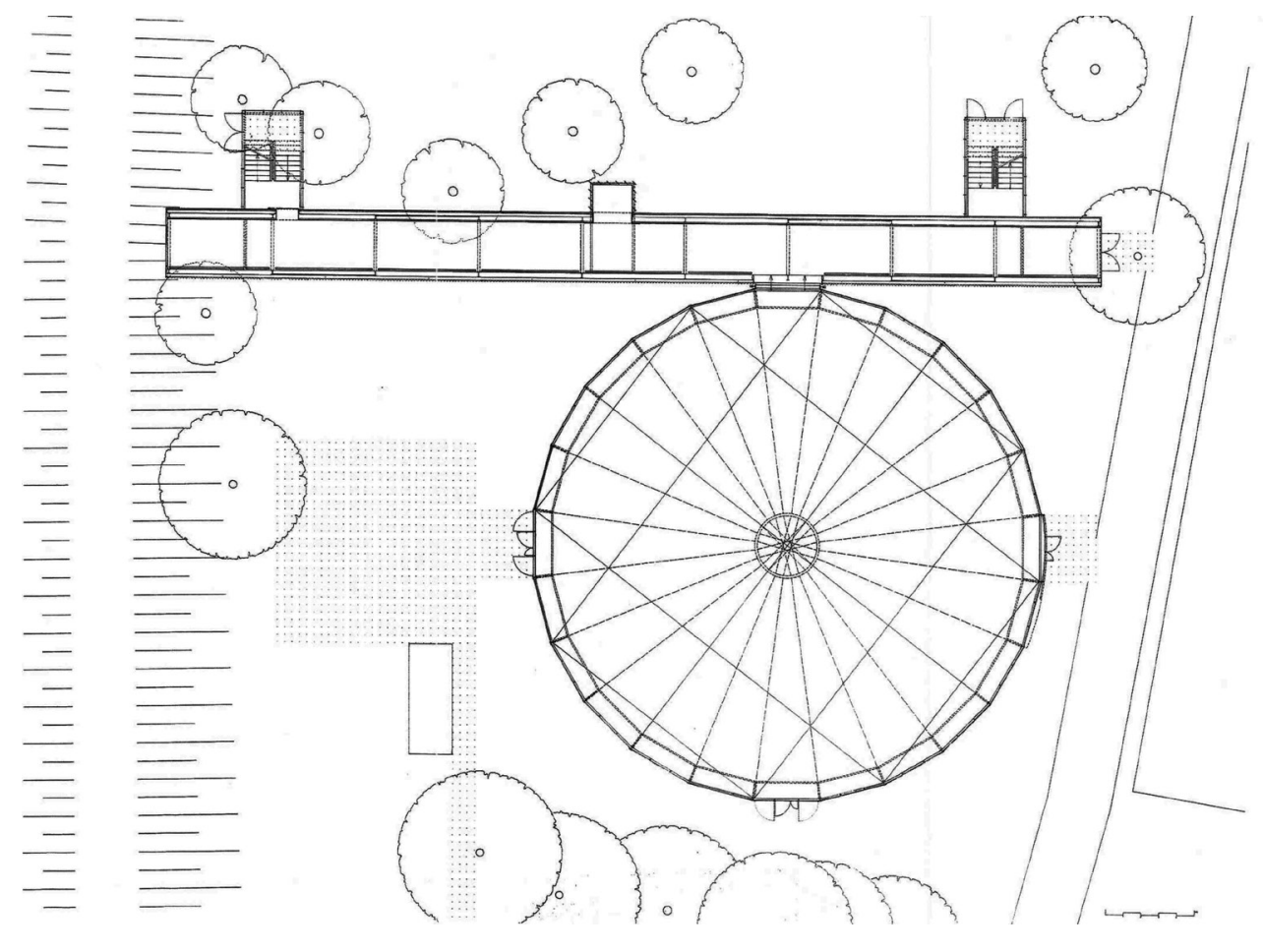

\section{FIG. 2. KRISCHANITZ, A.1988.
An der Traisen Pavillion en St. Pöt Planta y sección principales.
Fuente: Estudio Krischanitz.}

>> FIG. 3. KRISCHANITZ, A.1988. An der Traisen Pavillion en St. Pölten. Espacio ágora de presentación y Eucuentro de técnicos y ciudad

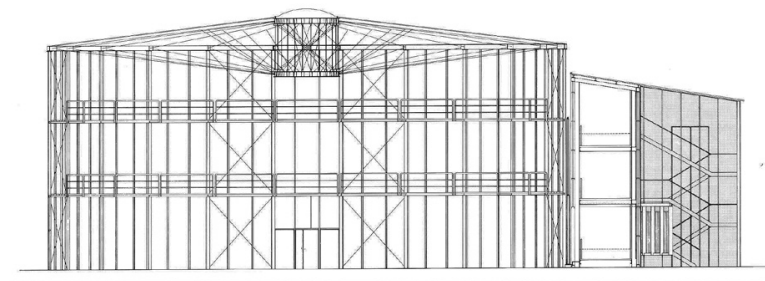

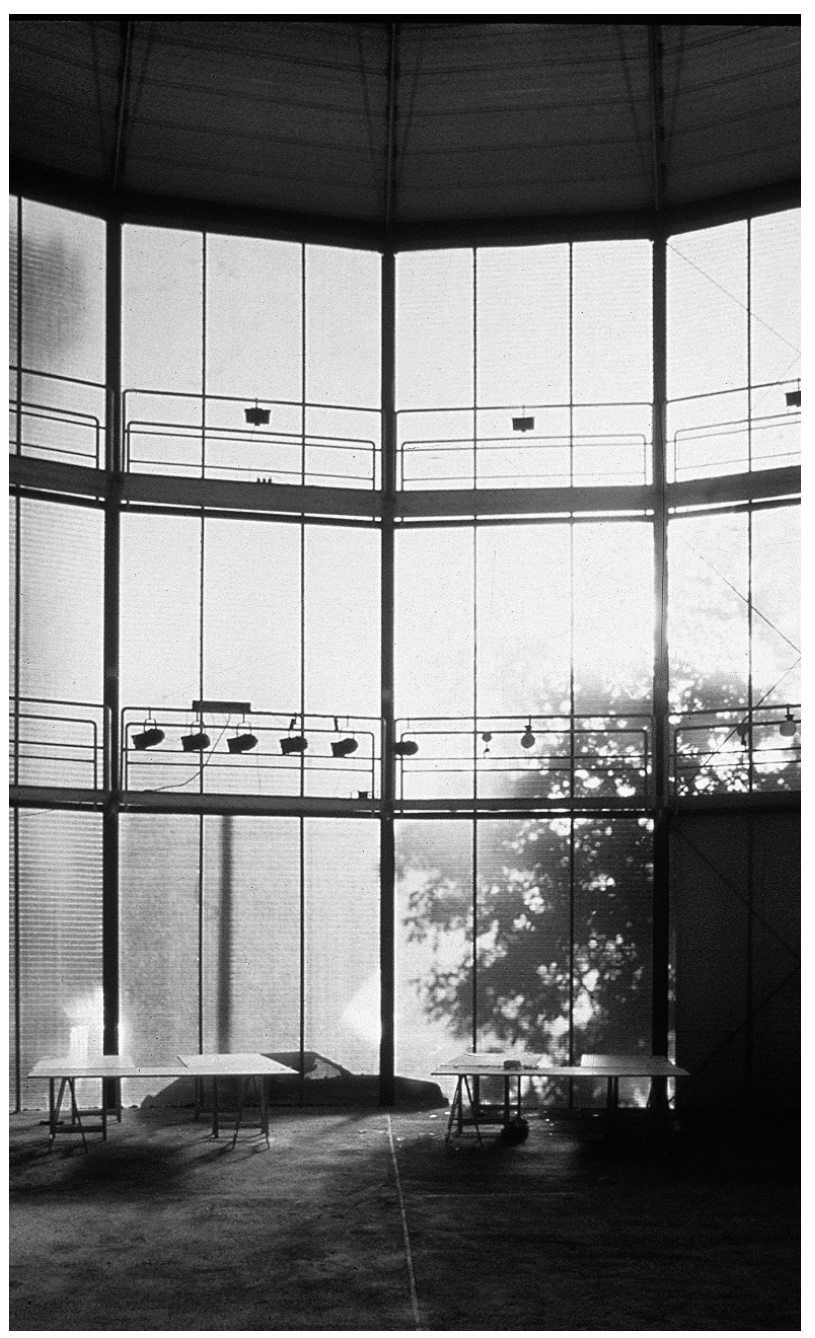

(E. Todd ${ }^{9}$. La arquitectura y las infraestructuras serán las principales inversiones de instituciones y gobiernos para mermar las diferencias entre las áreas periféricas y las centrales de Europa, y construir a través de ellas una identidad que las sitúe en el nuevo mapa económicamente unificado.

La ciudad de St. Pölten necesita un nuevo imaginario urbano: el experto en infraestructura y medios, F. A. Kittler, simula el territorio como un circuito tecnológico integrado (IC microchip) donde la ciudad es el nodo de una red virtual de interconexiones entre transporte, mercancía, energía e información. Sin embargo, frente a la traslación del fervor tecnológico y procesamiento de datos al territorio, fascinación tan propia del momento, el proyecto urbano de los "expertos internacionales" V. Magnago-Lampugnani y W. Wang ${ }^{10}$ apela al valor histórico y monumental de un repertorio de arquitecturas, "cuya composición representen los ideales públicos de la comunidad"11, y que deben ilustrar en St. Pölten el proyecto de ciudad: los talleres y oficinas de A. y G. Perret en Paris, la ampliación de Juzgados de Asplund en Goteborg, el KulturZentrum de Aalto en Wolzburg, la Casa del Fascio de Terragni, la Plaza de Moneo en Pamplona, las oficinas Faber\&Dumas de Foster, el Gobierno Civil de De la Sota, el concurso de viviendas de Trieste de Grassi, el Economist de los Smithson, el museo en New Haven de Kahn, la plaza de Sants de Viaplana, o el Prater Burg de Plecnik.

En St. Pölten toma forma la Collage City con que C. Rowe y K. Koetter (1975, Architectural Review) legitimaban años antes la autonomía del proyecto de arquitectura sobre el planeamiento urbano. Magnago-Lampugnani ${ }^{12}$ recorre los sucesivos intentos de urbanismo rígido y tecno-humanista que había colonizado la periferia de las ciudades medias europeas de los sesenta, duda de la posibilidad de recuperar los planteamientos tardo-modernos del Team10 y los Smithson (y de G. Grung, A. Van Eyck, O.M. Ungers), desmonta la inmediatez de los Krier, los planteamientos de corte histórico-contextualistas (R. Rogers, L. Quaroni, G. de Carlo), el vacío de la forma en Rossi, el metropolitanismo y la Cultura de la Congestión de Koolhaas, otra Citá Analoga como en Rossi. Para Magnago-Lampugnani, es Eisenman quien busca a través de la composición de un lenguaje fragmentario una alternativa para la comunicación y construcción de cultura urbana.

La buena acogida del pabellón no deja este collage fuera de la crítica. O. Kapfinger titula el artículo sobre la exposición "¿La fiesta del futuro?"13, donde advierte de la superposición de arquitecturas como piezas, fragmentos de ciudad ávidos de ser concursados, y la editora L. Waechter-Bohm arranca su crítica con el título "Mercado anual de conceptos" donde además de denunciar el popurrí de arquitecturas convocadas, se refiere con alivio al pabellón: la arquitectura de Krischanitz que acoge la exposición al menos "relativiza y desdibuja" el contenido didáctico e instructivo de "material fácilmente combustible en las mentes inflamables de los políticos"14.

La lógica de desarrollo rápido de proyectos icónicos por concurso que signifiquen una nueva identidad anuncia en St. Pölten, a pequeña escala, las estrategias políticas y celebratorias apoyadas por la inversión inmobiliaria empresarial que tienen lugar aceleradamente en la última década del siglo XX en otras ciudades europeas: Postdamer Platz en Berlin ${ }^{15}$, Milano II, el Plan Fiat Novoli en Florencia, La Défense en Paris, Euralille o Canary Wharf en Londres...

El pabellón An der Traisen es un ensayo construido de una actitud diferencial, que cuestiona la fragmentariedad, retórica formal y material que se despliega en la arquitectura centro-europea coetánea y asume la condición cultural -a veces política, que se vincula a la polis- de la obra de arquitectura.

No era éste el futuro urbano imaginado por $A$. Krischanitz y los críticos ${ }^{16}$ con el ágora-pabellón de $1988^{17}$, lugar simbólico de acercamiento de habitantes y expertos a las formas de producción de cultura y ciudad, cuyo distanciamiento habitante-experto denunciaba ya años antes Jürgen Habermas en la conferencia Modernity versus Postmodernity ${ }^{18}$ (1980). En ésta retrata el proceso de alejamiento de las formas de producción cultural -y urbana- de la vida real, la desvinculación del ciudadano del debate experto de la ciencia, la moral y las artes. A ello suma una crítica al gobierno de la voluntad política y la lógica predominantemente capitalista de producción de cultura cotidiana que algunos críticos, como la editora Waechter-Böhn, advierten en la exposición ${ }^{19}$. Habermas resume las distintas reacciones a esta situación y sostiene que las alternativas propuestas son en todo caso "conservadoras", y no suponen "Cabe pensar que el pabellón de Krischianitz apela a una de estas líneas de trabajo conservadoras, recupera la geometría formal moderna e incluso la experiencia estética sublime pre-moderna cuyos valores están siendo recuperados por críticos coetáneos como M. Hays. En Critical Architecture Between Culture ar arquitectura "como espacio entre la repre. eficiente de valores culturales pre-existentes y la autonomía de un sistema formal abstracto" (Hays 1984) ejemplificándolo con los proyectos de Mies van der Rohe ${ }^{21} y$ destaca aquellas arquitecturas que generan una propuesta autónoma -no adscrita a una retórica estilística o lingüística- y crítica en relación con la cultura contemporánea del momento en que se proyectan.

Esta reflexión de Hays es posible leerla en el pabellón de Krischanitz, cuya construcción material llena de ingenio (Kapfinger 1997)22 se resume en una forma definida entre el hallazgo y la invención, que condensa en una condición cultural singular sensiblemente distinta al proyecto de ciudad ideada y contenida en la exposición. Aunque riguroso en la definición técnica, la inmediatez y falta de acabado en la construcción del pabellón -no diseñar y sí asumir detalles industriales o estándar-, apela a la observación de otras relaciones y experiencias. "El resultado es una obra no-cerrada, incompleta, - 10 contrario las situaría en la industria cultural del Star System-, es una obra que ofrece un sutil tejido de relaciones de diferente peso, densidad e intensidad" (Steiner 1988) ${ }^{23}$

El pabellón An der Traisen de Krischanitz es un ensayo construido de una actitud diferencial, que cuestiona la fragmentariedad, retórica formal y material que se despliega en la arquitectura centro-europea coetánea y asume la condición cultural -a veces política, que se vincula a la polis- de la obra de arquitectura, buscando vincula a la polis- de la obra de arquitectura, buscando operatividad, pragmatismo y belleza alejada de otros
discursos disciplinares. Esta forma de proyectar es comun discursos disciplinares. Esta forma de proyectar es común
a algunos arquitectos coetáneos ${ }^{24}$ y resume un cambio o viraje en las tareas para la arquitectura a partir de entonces, tareas a las que Secchi (1984) ${ }^{25}$ apela pocos años antes, para subrayar la arquitectura como fuente y añoductor, para subrayar la arquitectura como fuente y productora de conocimiento, asi com aplicación técnica de los mismos. 
1 Premio de prestigio nacional concedido anualmente por la Asociacion de Empresas Constructoras austriacas. A. ula a la escena cultural junto a Otto Kapfinger y Angela Hareiter. Además de un intenso trabajo inicial en la restauración de la Werkbund y el Pabellón de la Secession, construye diversos pabellones temporales: Pabellón de Austria en la Feria del Libro Frankfurt (1994), el Kunsthalle I (1991-1992, desmontado) y Kunsthalle II (2001) Karlsplatz de Viena, Temporärar Kunsthalle en Berlí (2007 trasladado a Varsovia 2008). An der Traisen Pavillon es el primero de esta serie de insta
vinculadas con el arte y la cultura.

2 "La excepcionalidad de su naturaleza temporal, la oportunidad de la interrupción de la vida cotidiana y la maximización del efecto con un gasto mínimo, son parámetros y condiciones determinantes. (...) Un pabellón es subjetivo y proyectivo a la vez". En MORAVANSZKY, Á.; PIRHOFER, G.; KAPFINGER, O., 2015. pp.17-42. Traducción de los textos en inglés y alemán de la autora.

${ }^{3}$ Muestra de ello son las diferentes premisas de las obras del premio compartido, coetáneamente la Ampliación de de Coop-Himmelb(l)au era canonizada al incorporarse a la exposición Deconstructivist Architecture (1988) del MoMa Nueva York.

4 "Un efecto óptico iridiscente, como una membrana entre el exterior y el interior". En MORAVÁNSZKY, Á.; op. Cit. p.19.

${ }^{5}$ En la descripción del proyecto en el catálogo de la exposición el juego de conceptos como exponer, desvela revelar, velar, describe los efectos para los que está desaparezca -cosa que a pesar de los previsto, sólo desap diez años más tarde-: "Puede ser posteriólo desmontado o adaptado para otro uso. En algún momento, desaparecerá el objeto de exposición, y solo las huellas del pabellón desmontado serán el resultado arqueológico de la fundación de la nueva ciudad". En STEINER, D. et. Lat., 1988. p.27.

${ }^{6}$ KRISCHANITZ , A. Erläuterungs Bericht (Memoria original del proyecto) $P$. 2 .

${ }^{7}$ A. Krischanitz subraya evitar cualquier referencia hight-tech, insiste en su interés en la construcción low-cost para los

pabellones, cuya optimización estructural es propia de la
escuela de Salzburg. Lacada la estructura de color amarillo

y los tensores de azul (tambien asi en la Kunsthalle I Viena, 1992), "añaden, al contrario de lo que pudiera entenderse en obras de Rogers o Foster, una cierta cotidianeidad". (Entrevista Febrero 2017, incl. Tesis Doctoral de la autora)

8 BARTHES, R.1980. Mitologías. El mito hoy. Madrid: Mythologies, Editions du seuil.

${ }^{9}$ TODD, E., 1995. La invención de Europa, Barcelona: Tusquets ISBN 84-7223-868-7 (TODD, E., 1990. L'Invention de l'Europe, Editions du Seuil).

${ }^{10}$ WANG, W. "Die Repräsentation der Institution im Stadtraum " ("La representación de la institución en el
espacio de la ciudad") en STEINER, D. et. Lat. 1988, op. espacio de la ciuda
Cit. p.391-439.

11 WANG, W. op.cit. p.396

12 MAGNAGO-LAMPUGNANII,V. "Die Abwesende Utopie: Skizze der kritischen Geschichte der Städtebaulischen Leitbilder 1965-1985"' "'La utopía ausente: bocetos de una historia critica del imaginario urbano de 1965-1985") en STEINER, D. et. Lat. op. 1988, Cit.p.441-481.

${ }^{13}$ KAPFINGER, O., 1988. "Festplatz der Zukunft?. Geburt einer Hauptsadt - Austellung in St. Pölten" ("Fiesta del Futuro? La exposición dl nacimiento de la capital St Junio 1988.

${ }^{14}$ WAECHTER-BOHM,L. 1988.

${ }^{15}$ Es de interés comparar el pabellón de St.Pölten con el Info Box Postdamer Platz (Schneider y Schumacher, 19951999), aunque la escala de las capitales y las obras sean
desiguales, ambos pabellones son un centro de exposición desiguales, ambos pabellones son un centro de exposición pero en Berlin, por un módico precio los ciudadanos ciudad situada nueve metros por encima del niv de su calle. Allí planos, maquetas, cámaras en tiempo rel y un balcón mirador mostraban los cambios urbanos de la futura capital. Sobre ello dos plantas de oficinas de los arquitectos e ingenieros y coronándolo, las empresas promotoras y propietarias del suelo. Un dispositivo en el sentido foucaultiano que denotaba con su resolución arquitectónica y programática, la lógica de producción de ciudad poscapitalista que enmascaraba la exposición.

16 "Materiales contemporáneos, mesura y una construcción legible formulan un espacio público, de comunicación, urbanidad futura". WAECHTER BÖHM, L. 1988. Op cit.

${ }^{17}$ El pabellón fue desmantelado años más tarde, dejando atrás propuestas que proponían hacer de esta ciudad de provincias una capital. Treinta años más tarde cabe re-evaluar St. Pölten como muestra de laboratorio, que ciudad se ha producido: la lista de arquitectos que durante más de una década construyen la ciudad es extensa: los Konzertsaal de KKada, el Centro Cultural y de Exposiciones Konzertsaal de K. Kada, el Centro Cultural y de Exposicion como en los estudios de comunicación ORF de G. Peichl, son ejemplos de una arquitectura que encuentra en la retórica formal la aportacion a la ciudad. Apenas se percibe el Archivo y la Biblioteca Regional de K. Bily, P. Katzberger, M. Loudon. Baumschlager-Eberle, Adolph H. Kelz, dos proyectos que se muestran sosegados en cuanto a la forma, con patio y aterrazamiento en sus accesos a modo de vestibulos urbanos donde se produce el encuentro co acumulación de mobiliario y la usencia de ciudadanos, los funcionarios en esta otra capita.

${ }^{18}$ HABERMAS, J., \& BEN-HABIB, S. 1981. pp.3-14.

19 WAECHTER-BOHM,L. 1988. Op cit.

${ }^{20}$ HAYS, M.,1984. pp. 14-29.

21 Se refiere a los proyectos de Mies para Friedrichstrasse, 1922; Stuttgart Bank, 1928; Alexander Platz,1928. Hays posición: "Rechazamos reconocer problemas de forma. sólo problemas de construcción. La forma no es el objetivo de nuestro trabajo, sólo el resultado. La forma en sí misma no existe, la forma apunta a formalismo, y lo rechazamos" (citado por Hays de Johnson, Ph.C. "Mies Van der Rohe", 1947, MoMa: Exhibition Catalog).

22 En KRISCHANITZ, A.1997. p. 7, Otto Kapfinger se refiere a "Form(er)findung". La palabra Ertindung en aleman además de invención y hallazgo, que traduciŕamos comos,

${ }^{23}$ En STEINER D. 1990, pp.18-20.

24 "Algunos jovenes arquitectos de la periferia europea -y no en los centros -conforman una "disidencia" cuya cuestión común es actuar fuera del sistema de crítica y referencias establecido". STEINER, D. 1990.op.cit. Es posible identifica esta actitud en el desarrollo inicial de las primeras obraS de estudios como Riegler\&Riewe, Brand Huber\&Kniess, F.Geipel\&N.Michelin o Lacaton\&Vassal.

25 "'...)Búsqueda de un método proyectual diferente, sólo en algunos aspectos opuesto al del pasado, en el cual la atención se ha puesto primariamente sobre el problema del sentido, de las relaciones; esto es, de cuanto pertenece al contexto, a su factualidad y materialidad,
regla productiva". SECCHI, B., 1984.

BIBLIOGRAFÍA

HABERMAS, J., \& BEN-HABIB, S. 1981. Modernity versus Postmodernity. New German Critique, (22), 3-14.

HAYS, K. 1984. Critical Architecture: Between Culture and Form. Perspecta, 21, pp. 15-29. DOl:10.2307/1567078.

KAPFINGER, O., 1988. Festplatz der Zukunft?. Geburt einer Hauptsadt - Austellung in St. Pölten. Hemeroteca. Die

KRISCHANITZ, A. 2015. In conversation: Adolf Krischanitz -Otto Kapfinger, en MORAVÁNSZKY, Á.; PIRHOFER, G.; 3-7757-3482-0. p.17-42.

KRISCHANITZ, A.1997. Adolf Krischanitz, Barcelona: Gustavo Gili, 84-252-1730-X.

KRISCHANITZ,A. 1988. Erleuterung Bericht. Memoria de Proyecto, aportada por la oficina.

SECCHI, B., 1984. Le condizioni sono cámbiate. Casabella: Architettura come modificazione, n.498/9.

STEINER D. 1990, Beziehungen im Grenzbereich. Katalog der Austellung. Lucerna: Architektur Galerie. pp.18-20.

STEINER, D., SCHÖLLHAMMER, G., KNECHTL, C. EICHINGER, G. , 1988. Geburt einer Hauptstadt. Austellungs
Katalog. Viena: BuchQuadrat. ISBN 3-900870-004.

WAECHTER-BOHM,L. Jahremarkt der Konzepte. Hemeroteca. Die Presse. Spectrum, 25/26. Viena Junio 1988.

ABSTRACT

El artículo estudia el pabellón "An der Traisen" construido en 1988 por Adolf Krischanitz para albergar la exposición y jornadas de debate sobre el futuro crecimiento de St. Pölte como capital de Niederösterreich (Baja Austria). Si bien tanto el pequeño edificio temporal como la muestra estaban diseñados conjuntamente para presentar y representar la inminente transformación urbana, posible encontrar en e diálogo entre la arquitectura del proyecto y la arquitectura presentada en la muestra algunas contradicciones que lustran un punto de inflexion en la arquitectura coetanea. Mientras el proyecto de ciudad sobre el que reflexionan $V$. Magnago-Lampugniani y W. Wang, y cuya exposición ide D. Stent, G. Schiolly D. comorion construido con materiales ligeros y encomblados, que traslucían una luminosidad vibrante e intensa. Compuesto por dos piezas un esbelto prisma de tres nives albergab por exposición, y un cilindro, a modo de Tholos cubierto por una cúpula tensegrity, representaba el ágora cubmertó por donde avivar, con la celebración de actividades, debates y mesas de trabajo, la construcción de la urbs y la civitas de la futura capital.

PALABRAS CLAVE: Arquitectura ligera; pabellón temporal; exposición; forma.

MARTA PELEGRÍN es arquitecta y profesora asociada del Departamento de Proyectos Arquitectónicos de la Escuela Técnica Superior de Arquitectura de Sevilla, donde también es coordinadora de la Cátedra Blanca Sevilla.
Congrés d'arquitectura 2016

\author{
Lluís Comeron i Graupera
}

Recibido 2017.03.08 ::.: Aceptado 2017.03.09

El Col.legi d'Arquitectes de Catalunya va organitzar l'any 2016 un congrés entre professionals i obert a tota la ciutadania i institucions. Durant sis mesos es van realitzar debats, reflexions i ponències, per tal d'analitzar el context social, medioambiental i econòmic actuals, per tal d'identificar els nous reptes de l'arquitectura i plantejar el instruments professionals per assolir-los. (Font: COAC)

El canvi de segle ens ha portat una transformació en quasi tot el que emmarca les nostres vides i activitat professional sense precedents.

En l'arquitectura, la gran crisi ha provocat la ruptura sobtada en aquest procés de canvi, obligant a una ràpida comprensió i adaptació a la nova realitat i a preparar-nos pel que encara ha de venir.

El Col.legi d'Arquitectes de Catalunya, durant el segle passat, va afrontar situacions semblants organitzant congressos que van facilitar la trobada dels arquitectes, l'anàlisi i debat del que és rellevant en aquest moment, així per exemple: Congrés d'arquitectes en llengua catalana de 1931, el Congrés Arquitectura Catalana de 1980 i el Congrés UIA de 1996.

Front la situació actual, el COAC va proposar un congrés de format obert i participatiu, involucrant a escoles, institucions, administracions publiques i d'altres operadors per "construir una visió col-lectiva de futur i compartir-la”.

Durant sis mesos, de juny a octubre, i a través d'un centenar d'actes per als quals hem comptat amb la col. laboració de més de seixanta institucions, el Congrés ha servit de punt de trobada i reflexió per a prop de 4.000 assistents i més de 500 ponents, arquitectes i professionals d'altres disciplines.

Gran part de l'èxit obtingut, superior a les expectatives d'inici, rau en el seu format obert, buscant per damunt de tot una visió àmplia i polièdrica, sense apriorismes ni prejudicis. Aquestes opinions s'han recollit en comunicacions, totes consultables al web del Congrés, que donen una visió dels actes, les ponències o les opinions individuals que s'han sumat a la discussió. Una discussió que ha estat diversa en temàtiques, d'aproximació multidisciplinar i feta, efectivament, de la suma de visons personals més que de proclames corporativistes.

Aquest format innovador, lliure de temàtica i obert a tothom, ens ha permès copsar diferents realitats i il.luminar espais d'una professió, la d'arquitecte, que ha expandit, en els darrers deu anys, els seus límits i camps d'acció i interès. El Congrés s'ha obert així a noves formes d'exercici, nous espais d'oportunitat i noves maneres d'entendre la figura de l'arquitecte, reescrivint els límits i els àmbits que configuren una nova vocació de servei, d'acord amb les noves necessitats d'una societat immersa en canvis vertiginosos. Hem pogut descobrir nous àmbits d'expertesa i d'especialització, nous perfils professionals i, sobre tot, nous reptes i compromisos socials resumits durant les sessions de síntesi de la darrera setmana, que configuren la nova realitat del que és, avui, la nostra feina.

Confiem que amb el temps podrem confirmar que la visió construïda collectivament en aquests sis mesos, esdevingui un instrument útil davant els canvis incerteses i, sobre tot, millorant la nostra capacitat de trobar, potenciar i aprofitar noves oportunitats.

LLUIS COMERON I GRAUPERA es arquitecto por a ETSAB y decano del Col.legi d'Arquitectes de Catalunya. Ha combinado su actividad profesional con la docencia en la ETSAB y en la ETSAV. 